UDK: 624.042.7

DOI: https://doi.org/10.24867/06CG01Popadic

\title{
PROJEKAT ARMIRANOBETONSKE VIŠESPRATNE ZGRADE U NOVOM SADU PREMA EVROPSKIM STANDARDIMA
}

\section{THE PROJECT OF MULTI-STOREY REINFORCED CONCRETE BUILDING IN NOVI SAD ACCORDING TO EUROPEAN STANDARDS}

Nemanja Popadić, Fakultet tehničkih nauka, Novi Sad

\section{Oblast - GRAĐEVINARSTVO}

Kratak sadržaj - U prvom dijelu rada prikazan je projekat armiranobetonske višespratne zgrade $P o+P+5 \quad u$ Novom Sadu, a u drugom dijelu je analiziran uticaj položaja zidova za ukrućenje na odgovor konstrukcije prema evropskim standardima.

Ključne reči: Armiranobetonska zgrada, Evropski standardi, Seizmička analiza

Abstract - The first part of the work consist the project of multi-storey reinforced concrete building, basement+ ground floor +5 stories in Novi Sad, and the second part consist analysis of the impact of shear walls disposition on the seismic response of building structure according to European standards.
\end{abstract}

Keywords: Reinforced concrete building, European standards, Seismic analysis

\section{UVOD}

Projektnim zadatkom predviđeno je projektovanje armiranobetonske višespratne zgrade $\mathrm{Po}+\mathrm{P}+5$, skeletnog tipa sa zidovima za ukrućenje, prema evropskim standardima na osnovu zadatog arhitektonskog plana. Lokacija objekta je Novi Sad.

\section{TEHNIČKI OPIS}

\subsection{Arhitektonsko rješenje}

Objekat je u osnovi nepravilnog oblika, površine u osnovi $268 \mathrm{~m}^{2}$ i spratnosti podrum + prizemlje +5 spratova. Spratna visina podruma je $2,75 \mathrm{~m}$, prizemlja $3,90 \mathrm{~m}$ a tipskih spratova 2,68 m. Ukupna visina objekta iznad kote terena je 19,70 m. Podrum je najvećim dijelom predviđen da se koristi kao parking prostor, u prizemlju je smješten poslovni prostor i jedna stambena jedinica, dok je na ostalim spratovima smješteno po 5 stanova.

Krov je ravan, neprohodan. Vertikalna komunikacija između spratova ostvaruje se pomoću jednokrakog stepeništa i lifta. Fasadni zidovi su od termo blokova i obloženi demit fasadom, dok se pregradni zidovi izvode od giter bloka ili opeke. Podovi su izvedeni od parketa ili keramičkih pločica, u zavisnosti od namjene prostorija.

\section{NAPOMENA:}

Ovaj rad proistekao je iz master rada čiji mentor je bio dr Đorđe Lađinović, red. prof.
Na slici 1 dato je athitektonsko rješenje tipskog sprata.

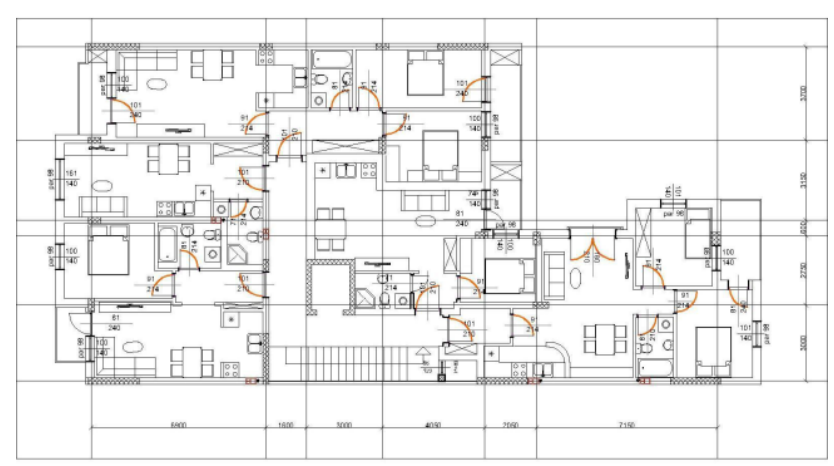

Slika 1. Osnova tipskog sprata

\subsection{Konstruktivni sistem zgrade}

Konstruktivni sistem objekta je skelet ukrućen armiranobetonskim platnima. Stubovi su različitih dimenzija i njihov poprečni presjek se smanjuje na višim spratovima, u skladu sa uslovima dopuštenih napona koje propisuje Evrokod [1,2,3]. Međuspratna je konstrukcija je projektovana kao puna AB ploča, direktno oslonjena na stubove. Zidovi za ukrućenje su raspoređeni po obodu objekta, oko lifta i oko stepeništa. Zidovi u podrumu su armiranobetonski i izvedeni po obimu garažnog dijela konstrukcije. Objekat se fundira na temeljnoj ploči debljine $50 \mathrm{~cm}$, a ispod nje se izvodi sloj šljunka i sloj mršavog betona. Hidroizolacija se postavlja ispod temeljne ploče i sa spoljašnjih strana podrumskih zidova. Dozvoljeni napon $u$ tlu je $200 \mathrm{kN} / \mathrm{m}^{2}$, marka betona svih elemenata nosećeg sistema je C25/30, a kvalitet armature B500B.

\subsection{Analiza opterećenja}

Za projektovanje i dimenzionisanje elemenata konstrukcije razmatrana su sva opterećenja koja mogu djelovati na konstrukciju u toku eksploatacije, kao i njihove najnepovoljnije kombinacije. Na zadatu konstrukciju djeluju sljedeća opterećenja:

- Stalno opterećenje

- Korisno opterećenje

- Opterećenje od snijega

- Opterećenje od vjetra

- Seizmičko opterećenje

Stalno opterećenje potiče od sopstvene težine konstruktivnih i nekonstruktivnih elemenata konstrukcije. Korisno opterećenje je usvaja prema standardu Evrokoda EN1991-1-1-2001 [1], intenzitet zavisi od namjene određene prostorije, a nanosi se jednako podeljeno površinsko opterećenje. Opterećenje snijegom se računa 
prema standardu EN1991-1-3-2003 [1], i takođe se nanosi kao jednakopodeljeno površinsko opterećenje. Opterećenje vjetrom se računa prema standardu EN1991-1-42005 [1] i nanosi se kao površinsko opterećenje, a zatim se konvertuje u linijsko. Seizmičko opterećenje se računa pomoću softveta Tower 6.0, a proračun se obavlja prema Evrokod standardu EN1998-1:2004 [3], primjenom multimodalne spektralne analize.

\subsection{Modeliranje konstrukcije i opterećenja}

Konstrukcija je modelirana u softverskom paketu Tower 6.0. Osnovni noseći sistem konstrukcije je skeletni sistem sa zidovima za ukrućenje. Na slici 2 prikazan je trodimenzionalni model konstrukcije.

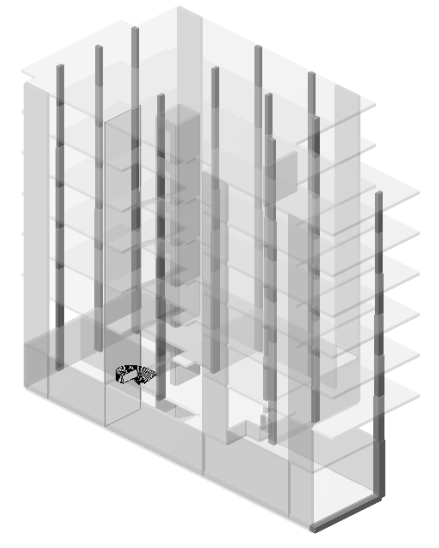

Slika 2. 3D model konstrukcije

Model se sastoji iz površinskih (ploče, zidovi) i linijskih (grede, stubovi) konačnih elemenata. Svi elementi su modelirani tako da njihove geometrijske i mehaničke karakteristike odgovaraju onima koje su zadate $u$ projektu. Prilikom modeliranja uzet je u obzir pad torzione i savojne krutosti elemenata konstrukcije, $\mathrm{i}$ to tako što je torziona krutost greda smanjena na veličinu koja odgovara $10 \%$ krutosti homogenog betonskog presjeka, dok je savojna krutost smanjena na $50 \%$. Savojna krutost stubova i zidova za ukrućenje smanjena je na vrijednost koja odgovara 50\% krutosti homogenog betonskog presjeka. Prilikom formiranja proračunskog modela korišćena je mreža konačnih elemenata veličine $0,4 \mathrm{~m}$. Tlo je modelirano pomoću Vinklerovog modela, koji omogućuje interakciju konstrukcije i podloge [4, 5].

Opterećenja se nanose na model kao linijska i površinska. Pomoću softvera je izvršena modalna analiza, na osnovu koje su dobijeni parametri koji služe za dalji proračun seizmičkih sila. Seizmički proračun je urađen multimodalnom spektralnom analizom. Proračun konstrukcije je izvršen prema linearnoj teoriji elastičnosti u kojoj se pretpostavlja geometrijska i materijalna linearnost.

\subsection{Proračunske kontrole}

Prema pravilniku [2, 3], potrebno je izvršiti sljedeće kontrole:

- Kontrola normalizovane vrijednosti aksijalnih sila u stubovima i zidovima

- Kontrola napona u tlu

- Kontrola relativnog spratnog pomjeranja

Normalizovanu aksijalnu silu je prema pravilniku EN1998-1:2004 [3] neophodno kontrolisati u primarnim seizmičkim elementima, odnosno stubovima, seizmičkim platnima i gredama. Dobija se iz seizmičke proračunske kombinacije prema graničnom stanju nosivosti. Za primarne seizmičke stubove projektovane na klasu duktilnosti DCM, vrijednost normalizovane aksijalne sile ne smije biti veća od 0,65 , dok kod seizmičkih zidova ova vrijednost ne smije biti veća od 0,40 . Naponi u tlu se kontrolišu u svrhu provjere da li je usvojeno adekvatno temeljenje objekta i u ovom slučaju potrebno je obezbjediti nosivost tla od $200 \mathrm{kPa}$. Kontrola napona u tlu se radi za anvelopu uticaja eksploatacionih neseizmičkih i seizmičkih opterećenja. Horizontalna spratna pomjeranja spadaju u domen kontrole graničnog stanja upotrebljivosti i pravilnik EN1998-1:2004 [3] propisuje dopuštene vrijednosti za dozvoljena relativna spratna pomjeranja. Kontrolišu se za eksploatacionu seizmičku kombinaciju opterećenja.

Nakon analize zaključeno je da konstrukcija zadovoljava uslove svih prethodno nabrojanih kontrola.

\subsection{Dimenzionisanje i armiranje elemenata}

Dimenzionisanje elemenata konstrukcije je izvršeno $u$ softverskom paketu Tower 6.0 i dimenzionisani su sljedeći elementi:

- Temeljna ploča

- Ploča prizemlja

- Ploča tipskog sprata

- Ram u osi C

- Ram u osi 2

- Ploča stepeništa

Dimenzionisanje je izvršeno u skladu sa pravilnikom Evrokod [1, 2, 3], prema uticajima mjerodavnih graničnih kombinacija. Svi konstruktivni elementi su od betona klase C25/30 i armirani su rebrastom armaturom B500B.

\section{UTICAJ POLOŽAJA ZIDOVA ZA UKRUĆENJE NA ODGOVOR KONSTRUKCIJE SAGLASNO EC8}

\subsection{Uvod}

Prema EC8 [3] pored otpornosti i krutosti konstrukcije u dva pravca, zahtijeva se torziona otpornost i krutost konstrukcije. Horizontalno seizmičko kretanje je fenomen u dva pravca, pa konstrukcija zgrade mora da bude sposobna da se odupre horizontalnim dejstvima u bilo kom pravcu. Da bi se ovo postiglo, potrebno je rasporediti noseće elemente u osnovi međusobno ortogonalno, tako da se obezbijede slične karakteristike krutosti i otpornosti u oba glavna pravca. Tako treba da se ograniči nastanak prekomjernih pomjeranja koje mogu da dovedu do nestabilnosti usljed efekata drugog reda ili do prevelikih oštećenja.

Osim bočne otpornosti i krutosti, konstrukcije zgrada treba da posjeduju i adekvatnu torzionu otpornost i krutost sa ciljem da se smanji nastajanje torzionih pomjeranja usljed kojih dolazi do neravnomjernog naprezanja različitih konstrukcijskih elemenata. To se postiže postavljanjem glavnih nosećih elemenata, koji se suprotstavljaju seizmičkim dejstvima, bliže obimu zgrade. Pravilnim izborom dispozicije, kao i pravilnim rasporedom konstruktivnih elemenata sprečava se pojava velikog ekscentriciteta centra mase i centra krutosti, usljed čega se 
od dejstva seizmičkih sila javljaju veliki momenti torzije koji dalje prouzrokuju velika pomjeranja i velike uticaje.

Pri izboru oblika zgrade u osnovi, prednost je uvijek na strani sažetih i simetričnih osnova, dok dugačke, razuđene, nesimetrične i nepravilne osnove treba da se izbjegavaju. Simetrijom zgrade u osnovi, postiže se jednostavnost konstrukcije i translatorno pomjeranje tavanice. U odnosu na nesimetrične, ovakve zgrade se odlikuju većom seizmičkom otpornošću. Kod nesimetričnih osnova, teško je obezbjediti poklapanje centra mase i centra krutosti, usljed čega se javlja torziranje zgrade u osnovi. Uticaji izazvani torziranjem mogu biti značajni i kod obodnih elemenata, pa čak i prevazići uticaje translatornog pomjeranja.

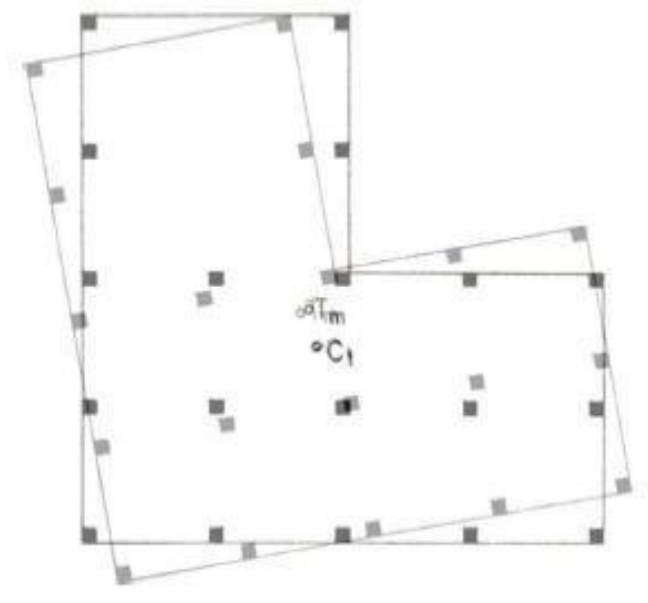

Slika 3. Torziranje zgrade u osnovi

Ipak, ni simetrične zgrade nisu u potpunosti oslobođene torziranja osnove. Poklapanje centra mase i centra krutosti je uvijek samo idealizacija. Uz to, i idealno simetrična zgrada postaje nesimetrična nakon prvog oštećenja. Ukoliko se nesimetrična zgrada mora raditi, poželjno je rastaviti je razdjelnicama na niz prostih i simetričnih dijelova. Ako ni to nije moguće, treba da se teži maksimalnom poklapanju centara krutosti i mase. Konstrukcija se u osnovi može smatrati torziono oslonjenom u centru krutosti, a napadnuta seizmičkom silom u centru mase.

U vertikalnom smislu, treba da se teži jednoličnosti konstrukcije. Svaka nesimetrična promjena dovodi do neželjenih torzionih momenata. Kod zgrada sa većom visinskom razlikom, poželjno je dijelove zgrada različite spratnosti dilatirati, posebno ako je visinska razlika nesimetrična [4].

Prema Evrokodu 8 [3] definisani su kriterijumi regularnosti konstrukcije dopunjujući načelne koji se odnose na simetričnost, uniformnost... Pri tome konstrukcija i dalje može biti projektovana kao neregularna, ali uz uslov zadovoljenja strožih uslova i/ili nemogućnost korišćenja pojednostavljenih metoda proračuna.

\subsection{Ponašanje konstrukcije u zavisnosti od promjene položaja zidova za ukrućenje}

U ovom dijelu biće analizirana tri modela konkretne konstrukcije sa različitim rasporedima zidova za ukrućenje. Plan je da se pokaže kako utiče raspored zidova za ukrućenje na sledeće parametre:
- Pomjeranje etaža konstrukcije u dva međusobno ortogonalna pravca

- Analiziranje uticaja udaljenosti centra krutosti konstrukcije na oblike oscilovanja

Na slikama 4, 5, 6 i 7 biće prikazani rezultati pomjeranja krovne ploče u dva glavna pravca za sva 3 navedena modela, kao i uticaj položaja zidova u odnosu na centar krutosti na periode oscilovanja konstrukcije.

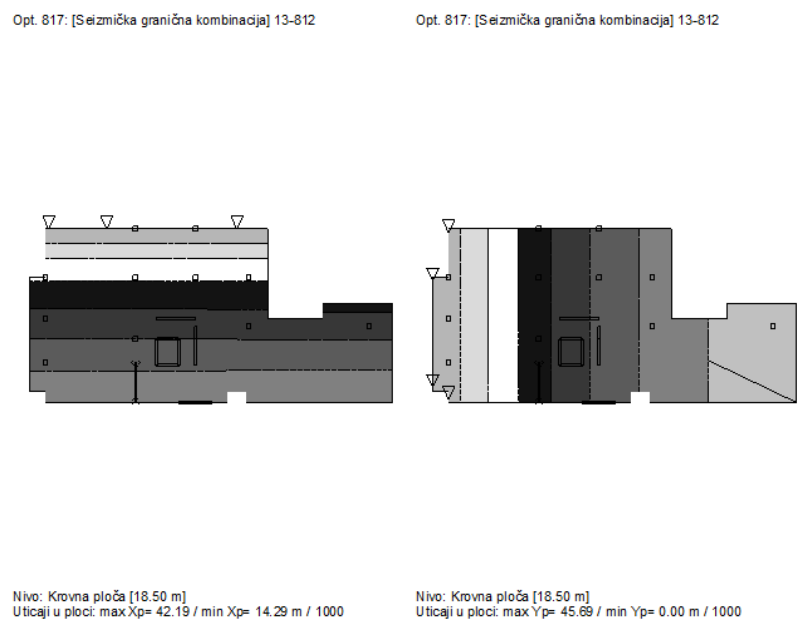

Slika 4. Pomjeranja krovne ploče u dva glavna pravcaModel 1

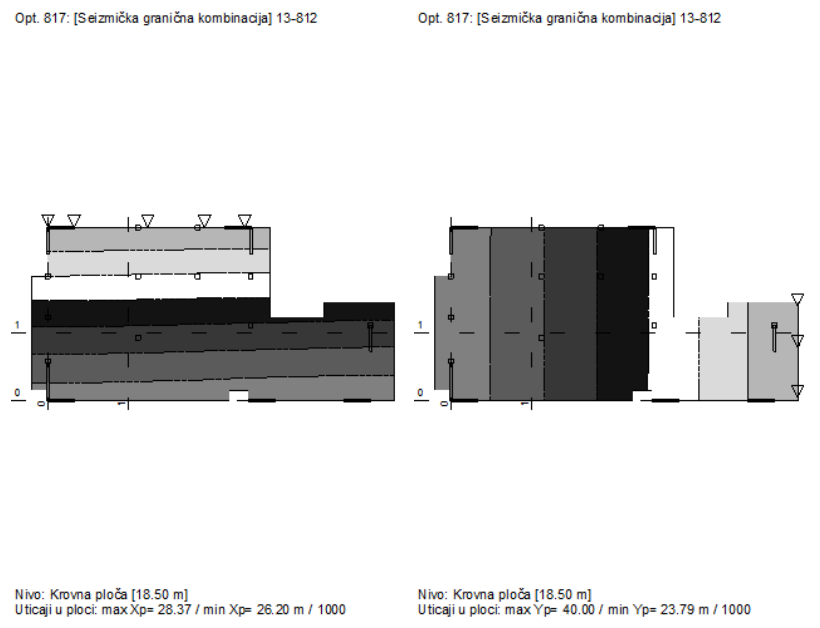

Slika 5. Pomjeranja krovne ploče u dva glavna pravcaModel 2

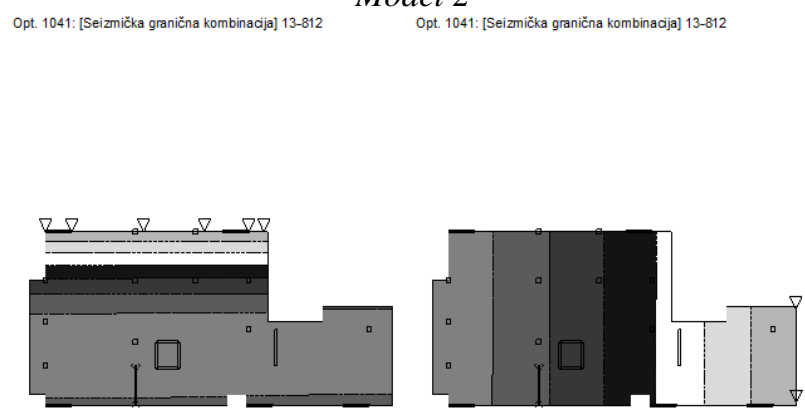

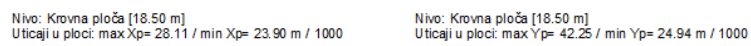

Slika 6. Pomjeranja krovne ploče u dva glavna pravca-Model 3 


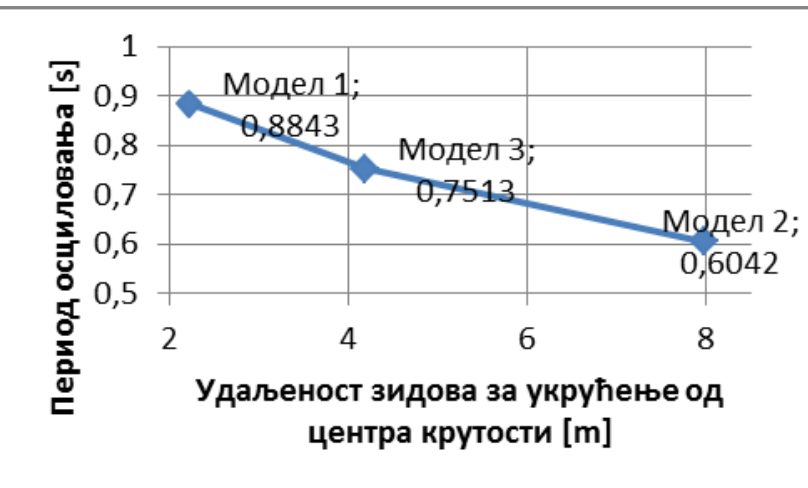

Slika 7. Uticaj udaljenosti zidova za ukrućenje od centra krutosti na periode oscilovanja konstrukcije

\section{ZAKLJUČAK}

Analizom prethodna tri modela, došlo se do zaključka da se po pitanju torzionih efekata, tj. pomjeranja i oblika oscilovanja izazvanih torzijom, najbolje ponaša model 2 konstrukcije kod koga su zidovi za ukrućenje raspoređeni po obodu konstrukcije. To je potvrda teorije da je po pitanju torzije najbolje postaviti zidove po obodnom dijelu konstrukcije.

Prethodno je analiziran model 1, kod koga su zidovi oba pravca pomjereni ka sredini konstrukcije i analizirano je ponašanje konstrukcije $u$ pogledu pomjeranja u dva pravca, oblika oscilovanja i perioda oscilovanja konstrukcije. Model 1 je po pitanju uticaja torzionih efekata na seizmički odgovor konstrukcije najnepovoljniji iz razloga lošeg rasporeda seizmičkih zidova.

Kao posljednji, analiziran je model 3 koji je i obrađen u ovom radu, i gdje se nastojalo da se postigne kompromis arhitektonskih, funkcionalnih i statičkih parametara. Takođe, analizirajući oblike oscilovanja, primjećuje se da se prelaskom sa modela 1 na model 2 smanjuje i torziranje osnove, dok model 3 predstavlja prelazni model između prva dva.

Zaključak teorijskog dijela bio bi potvrda teorija koje su postavljene na početku ovog poglavlja. Analizom svih ovih modela, čiji su rezultati grafički prikazani, dolazimo do sljedećih zaključaka:
- Zidovi u X i Y pravcu sprečavaju translatorno pomjeranje konstrukcije objekta ali nisu garancija da neće biti torziranja osnove zgrade i njenih nepovoljnih efekata u slučaju seizmičkog opterećenja. Pored postojanja zidova X i Y pravca, bitan je i njihov raspored kako bi se spriječilo torziranje zgrade $\mathrm{u}$ osnovi.

- Zidovi za ukrućenje, tačnije njihov položaj treba da bude što udaljeniji od centra krutosti konstrukcije kako bi se što efikasnije suprotstavili torzionom momentu (idealan položaj jeste obodni dio konstrukcije).

- Čak i manji ekscentriciteti sa nepovoljnim rasporedom seizmičkih zidova mogu da izazovu velike torzione efekte a samim tim veća pomjeranja i veće uticaje, naročito u vertikalnim elementima koji se nalaze po obimu konstrukcije.

- Sprečavanje neželjenih torzionih efekata usljed seizmičkog opterećenja na konstrukciju zavisi kako od broja seizmičkih zidova, tako i od njihovog rasporeda koji je veoma bitan.

\section{LITERATURA}

[1] Evrokod 1: Dejstva na konstrukcije, Beograd, 2009.

[2] Evrokod 2: Proračun betonskih konstrukcija, Beograd, 2009.

[3] Evrokod 8: Proračun seizmički otpornih konstrukcija, Beograd, 2009.

[4] Dr Zoran Brujić: „Betonske konstrukcije u zgradarstvu prema Evrokodu“ - skript, FTN Novi Sad, 2018

[5] S. Stevanović: Fundiranje, Naučna knjiga, Beograd 1989.

\section{Kratka biografija:}

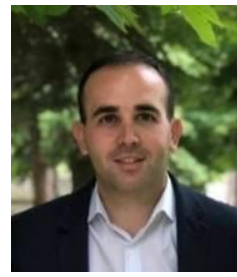

Nemanja Popadić rođen je u Trebinju 1993. god. Master rad na Fakultetu tehničkih nauka iz oblasti Građevinarstva - Seizmička analiza konstrukcija odbranio je 2019.god.

kontakt: nemanjapopadic@live.com 